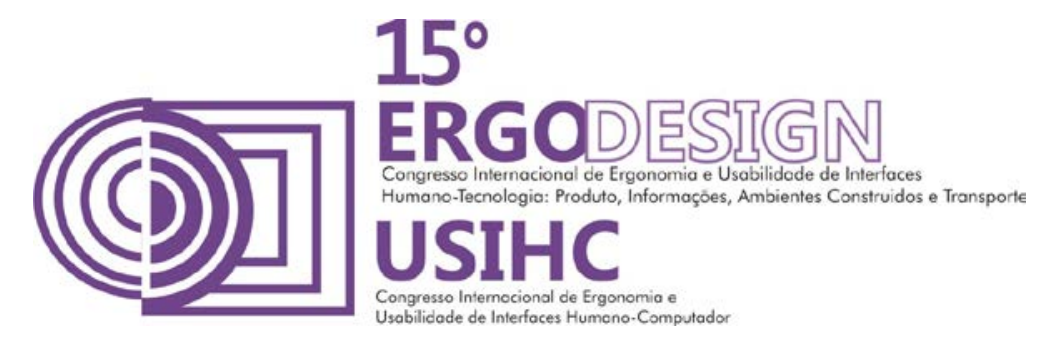

\title{
HUMAN-CENTERED DESIGN: UMA EXPERIÊNCIA SOBRE O CICLISMO NO RECIFE
}

\section{HUMAN-CENTERED DESIGN: AN EXPERIENCE ABOUT CYCLING IN RECIFE}

\author{
Oliveira, Luan \\ Universidade Federal Rural de Pernambuco, Estudante de Graduação \\ e-mail: luan.oliveira1992@hotmail.com
}

\begin{abstract}
RESUMO
Este trabalho apresenta uma experiência de Human-Centered Design como norte para a resolução de problemas com os ciclistas, especialmente aqueles que utilizam o sistema de público de aluguel de bicicletas, o BikePE.

Palavras-chave: Human-Centered Design, ciclismo, usabilidade
\end{abstract}

\begin{abstract}
This paper presents an EXPERIENCE of Human-Centered Design as guide for the resolution of problems with cyclists, especially those using the public bicycle rental system, BikePE.

Keywords: Human-Centered Design, cycling, usability
\end{abstract}

\section{INTRODUÇÃO}

Nas grandes metrópoles brasileiras, a locomoção, mesmo que em curtos espaços, torna-se algo lento. Isso ocorre devido a um contesto relacionado muitas vezes ao transporte, trânsito, infraestrutura e gestão da mobilidade urbana que se encontram despreparadas ou inexistentes. Como consequência dessa situação, os sistemas de circulação tem se degradado rapidamente. 


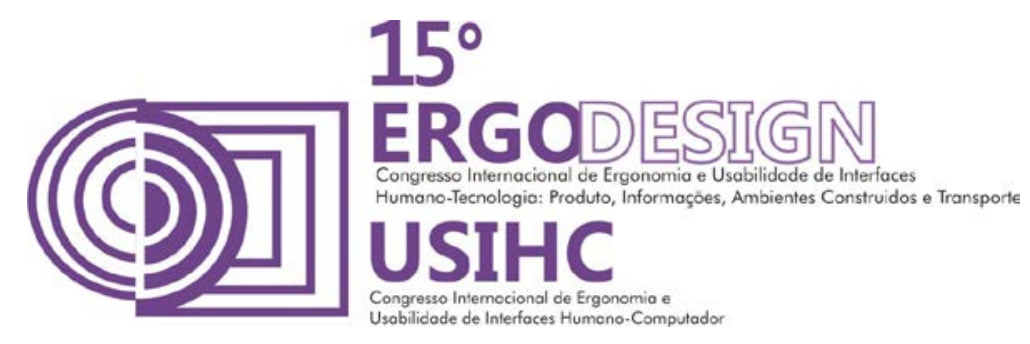

Nesse âmbito, no qual a cultura de circulação é de predominância por automóvel como uma solução para circulação, e também para a segurança, é crescente o cenário de congestionamentos, de privatização do espaço público e de concentração da mobilidade urbana. Muitos espaços públicos deixam de ser apreciados por pessoas que convivem no dia a dia em espaços próximos, causando assim um desconhecimento de sua própria cultura.

Neste cenário, o Sistema BikePE, através de uma infraestrutura de T.I, oferece a possibilidade de aluguel de bicicletas à toda comunidade, mediante um cadastro simples. Apesar da ideia se parecer, a primeira vista, bastante prática, e com capacidade de resolver o problema encontrado, é necessário olhar a solução com esmero.

\section{METODOLOGIA}

Para este estudo propulsemos conhecer a experiência dos usuários de bicicletas da cidade do Recife-PE, especialmente usuários do sistema BikePE visando tornar mais harmônica a convivência. Como processo para nos nortear em direção à inovação, adotamos o processo do Human - Centered Design (HCD). O HCD é um processo e também um conjunto de técnicas usadas para criar novas soluções para o mundo. As soluções incluem produtos, serviços, ambientes, organizações e modos de interação(IDEO,2009). O processo começa por examinar as necessidades e comportamentos das pessoas que queremos afetar com as nossas soluções.

Busca-se ouvir e entender o que as pessoas querem(Kuo,2012). O buscar entender, isso é sentir as necessidades das pessoas, no processo do HCD essa busca recebe o nome de lentes da desejabilidade. Ver-se o mundo através desta lente durante todo o processo de design. Dado que foi identificado uma série de o que é desejável, inicia-se o processo de observação das soluções, agora, pelas lentes da viabilidade.

O processo do HCD começa com um Design Challenge específica e passa por três fases principais: ouvir, criar e entregar. O processo irá mover sua equipe a partir de observações concretas sobre as pessoas, para o pensamento abstrato como você descobrir insights e temas, em seguida, volta para o concreto com soluções concretas.

\subsection{Ideação}

No processo de ideação é necessário, mas do que nunca sentir as necessidades do usuário. Definitivamente, as lentes da desejabilidade são necessárias para encontrar uma solução para o problema que existe, e não criar problemas para a solução a ser feita. Para perceber os problemas utilizamos da entrevista e da observação participante. Essas duas técnicas foram escolhida visando não interferir nas falas dos usuários. Após os dados coletados, segue-se para a etapa de categorização das anotações feitas, com essa categorização, podemos ter uma ideia de quais os principais aspectos deixam a desejar. 


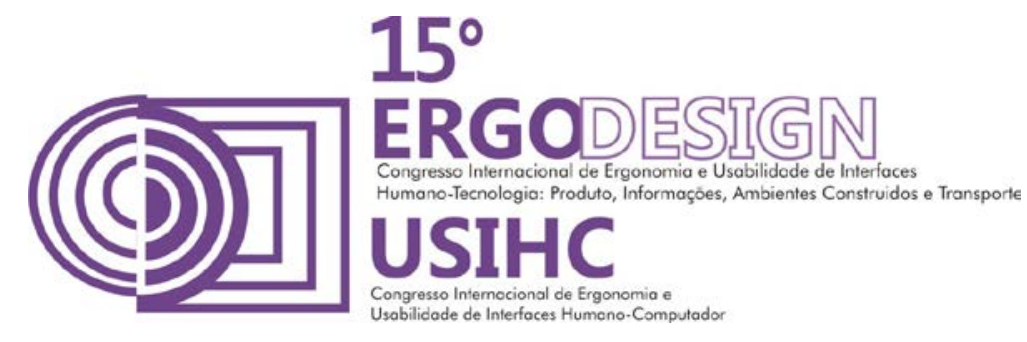

\subsection{Avaliação}

Após todas as categorizações seguimos para a etapa do brainstorm, no qual todos os membros elegiam possíveis soluções tendo em vista uma categoria apresentada, isso, sem nenhuma influência de um outro participante. Tendo toda uma gama de possíveis soluções em mau, o próximo passo é discutir tudo o que foi produzido, e criar soluções que atendam aos problemas, e incluam as soluções para as categorias.

\section{CONCLUSÃO}

O processo de design centrado no usuário permite a criação de soluções sem a interferência de um ator que ver de fora o processo. As soluções criadas buscam resolver diversos problemas tendo como norte sempre a experiência do usuário.

\section{REFERÊNCIAS BIBLIOGRÁFICAS}

IDEO. Human-Centered Design Toolkit, 2009.

Kuo, Cheng-Lang ,Applied Ergonomics - Using Human-Centered Design to improve the assault rifle. 